\title{
Desafios e dificuldades enfrentadas pelo enfermeiro docente para 0 exercício da docência no ensino superior
}

\author{
Challenges and difficulties faced by the teaching nurse for teaching in higher education \\ Desafíos y dificultades enfrentadas por el enfermero docente para el ejercicio de la \\ docencia en la enseñanza superior
}

Francisco Lucas de Lima Fontes ${ }^{1 *}$, Rosane da Silva Santana ${ }^{2}$, Josélia Costa Soares ${ }^{1}$, Rosa Irlania do Nascimento Pereira ${ }^{1}$, Ilana Maria Brasil do Espírito Santo ${ }^{3}$, Márcia Sandra Rêgo de Sousa ${ }^{3}$, Germano Soares Martins ${ }^{1}$, Celiane Alves de Araújo ${ }^{1}$, Maria de Jesus Monteiro da Silva ${ }^{4}$, Alzira de Sousa Silva Neta ${ }^{1}$, Gildecy Teixeira Coimbra ${ }^{5}$, Mércia Cycilia de França Lopes ${ }^{1}$, Layany Feitosa Pinho ${ }^{1}$, Nayla Karine Barros da Silva ${ }^{1}$, Anália Maria Alves da Silva Costa ${ }^{1}$.

\section{RESUMO}

Objetivo: Identificar desafios e dificuldades enfrentadas pelo enfermeiro docente para o exercício da docência no ensino superior. Métodos: Pesquisa de campo qualitativa descritiva desenvolvida com 12 enfermeiros que lecionavam aulas teóricas em uma instituição de ensino escolhida por dispor do ensino de Enfermagem há mais de 40 anos. A coleta dos dados ocorreu entre fevereiro e abril de 2018, respeitando-se os princípios éticos e legais da pesquisa com seres humanos. Resultados: Identificou-se por meio dos relatos desafios relacionados à infraestrutura da instituição, ao alunato, à desvalorização do ensino, às tecnologias, à sobrecarga de trabalho e ao próprio professor. Conclusão: Para que haja um ensino de qualidade é importante que todas os desafios encontrados neste estudo sejam solucionados por meio de investimentos em infraestrutura, programas de incentivo ao desenvolvimento de aptidões voltados aos jovens desde o ensino básico e mecanismos de envolvimento docente com a instituição de ensino e seus atores.

Palavras-chave: Prática do Docente de Enfermagem, Ensino de Enfermagem, Docentes de Enfermagem, Ensino Superior.

\section{ABSTRACT}

Objective: To identify the challenges and difficulties faced by the teaching nurse for teaching in higher education. Methods: Descriptive qualitative field research developed with 12 nurses who taught theoretical classes in a teaching institution chosen for Nursing teaching for more than 40 years. The data collection took place between February and April 2018, respecting the ethical and legal principles of human research. Results: It was identified through the reports challenges related to the institution's infrastructure, alunato, the devaluation of education, technologies, workload and the teacher himself. Conclusion: In order to ensure quality education, it is important that all the challenges found in this study be solved through investments in infrastructure, programs to encourage the development of skills directed at young people from basic education, and mechanisms of teacher involvement with the institution of teaching and its actors.

Keywords: Nursing Faculty Practice, Education Nursing, Faculty Nursing, Education Higher.

\footnotetext{
${ }^{1}$ Faculdade UNINASSAU - Campus Redenção. Teresina, Piauí, Brasil. *E-mail: lucasfontesenf@hotmail.com

${ }^{2}$ Universidade Federal do Ceará. Fortaleza, Ceará, Brasil.

${ }^{3}$ Centro Universitário Uninovafapi. Teresina, Piauí, Brasil.

${ }^{4}$ Centro Universitário Santo Agostinho. Teresina, Piauí, Brasil.

${ }^{5}$ Associação de Ensino Superior do Piauí. Teresina, Piauí, Brasil.
} 


\section{RESUMEN}

Objetivo: Identificar desafíos y dificultades enfrentadas por el enfermero docente para el ejercicio de la docencia en la enseñanza superior. Métodos: Investigación de campo cualitativa descriptiva desarrollada con 12 enfermeros que enseñaban clases teóricas en una institución de enseñanza escogida por disponer de la enseñanza de Enfermería desde hace más de 40 años. La recolección de los datos ocurrió entre febrero y abril de 2018, respetando los principios éticos y legales de la investigación con seres humanos. Resultados: Se identificó por medio de los relatos retos relacionados con la infraestructura de la institución, el alunato, la devaluación de la enseñanza, las tecnologías, la sobrecarga de trabajo y el propio profesor. Conclusión: Para que haya una enseñanza de calidad es importante que todos los desafíos encontrados en este estudio sean solucionados a través de inversiones en infraestructura, programas de incentivo al desarrollo de aptitudes dirigidas a los jóvenes desde la enseñanza básica y mecanismos de participación docente con la institución de la enseñanza y sus actores.

Palabras-clave: Práctica del Docente de Enfermería, Educacíon en Enfermaría, Docentes de Enfermería, Educación Superior.

\section{INTRODUÇÃO}

A atuação na docência do ensino superior, conforme prevista em lei, é permitida através da aquisição do título de mestre ou doutor, titulações estas que possibilitam aprofundamento de conhecimento em uma área específica de atividade, conforme artigo no 66 da Lei de Diretrizes e Bases da Educação (LDB) vigente (BRASIL, 1996).

Cursos de pós-graduação stricto sensu (mestrado e doutorado), em sua maioria, privilegiam mais a produção científica do que o preparo pedagógico. Pouco se exige em termos didáticos, pois quando se fala em formação de professores é frequente o pensamento de formação para o ensino na educação mais básica em detrimento da educação superior, como se esta última fosse algo insignificante (CAMPOS VTB, 2012).

Para Pimenta SG e Anastasiou LCG (2014), o preparo para a docência no ensino superior fica sob responsabilidade de uma única disciplina presente nos programas de especialização, mestrado e doutorado, frequentemente intitulada "Metodologia do Ensino Superior", "Métodos e Técnicas do Ensino" ou "Didática do Ensino Superior". Os autores pontuam ainda a insuficiente carga horária e a oportunidade dessa disciplina como os únicos momentos para reflexão sobre sua função docente, o processo ensino-aprendizagem, 0 planejamento, a organização, a metodologia, os critérios de avaliação e as circunstâncias onde atuam.

As oportunidades para os profissionais bacharéis têm aumentado na educação superior com a multiplicação das instituições particulares de ensino em todo o Brasil (NASCIMENTO VSO, 2017). O acesso ampliado às instituições de ensino superior fez com que a demanda por profissionais docentes aumentasse. Essas alterações e os recentes estudos na área da docência ressaltam uma transformação de cenário do ensino superior, antes focado na mera transmissão de conhecimentos, hoje envolvido com a mediação e construção de saberes (INEP, 2014; SALES MPS e MACHADO LB, 2013).

Devido a essa nova conformação do papel docente, acrescido às várias condições feitas a este profissional atualmente, que compreende contínua atualização, alta competitividade, aperfeiçoamento técnico, valorização do currículo e jornada exaustiva de trabalho, o professor tem de se reinventar ao enfrentar os obstáculos oriundos do ser e do fazer pedagógico que se destacam, especialmente, quando leva-se em consideração o espaço existente na formação de bacharéis que atuam no ensino superior (VARELA DSS et al., 2016).

Além da não formação pedagógica, o docente bacharel contemporâneo, defontra-se com vários outros obstáculos, dentro e fora da sala de aula, que dificultam os afazeres docentes, além da influência contínua de alterações nos diversos setores da sociedade. Essas dificuldades e mudanças, que englobam valores e condutas, por vezes favorecem a desvalorização do ensino (AGNELLI JCM e NAKAYAMA BCMS, 2018). 
Diante do explanado, o objetivo do presente estudo foi identificar desafios e dificuldades enfrentadas pelo enfermeiro docente para o exercício da docência no ensino superior.

\section{MÉTODOS}

Trata-se de uma pesquisa de campo qualitativa descritiva derivada de um projeto denominado "Percepções de enfermeiros docentes sobre as práticas pedagógicas em uma instituição pública de ensino superior em Teresina-PI", que teve aprovação do Comitê de Ética em Pesquisa da Faculdade de Ciências e Tecnologia do Maranhão (FACEMA) com no CAAE 82103318.7.0000.8007 e no de parecer 2.492.663. Tal projeto resultou em três artigos científicos que utilizaram a mesma metodologia, porém temáticas e objetivos distintos.

O estudo ocorreu com 12 enfermeiros docentes que ministravam aulas teóricas em uma universidade pública federal, escolhida por dispor do ensino de Enfermagem há mais de 40 anos. A referida instituição localiza-se em Teresina, capital do Piauí, e a coleta dos dados deu-se por meio de entrevista semiestruturada entre os meses de fevereiro a abril de 2018, no Departamento de Enfermagem da instituição.

O roteiro de entrevista semiestruturada elaborado para este estudo pautou-se em duas seções: a primeira com informações pessoais e profissionais com vistas a descrever o perfil dos entrevistados; e a segunda constituída por questões abertas sobre a temática, com vistas ao alcance do objetivo apresentado.

A busca pelos participantes aconteceu de maneira aleatória até se chegar a amostra final. Foi adotado como critério de inclusão somente os enfermeiros docentes de disciplinas teóricas com mínimo de vivência de três anos; e de exclusão aqueles enfermeiros docentes lotados exclusivamente em atividades práticas, ou seja, em campos de estágio. Utilizou-se como parâmetro de encerramento das entrevistas a técnica de saturação das falas de Minayo MCS (2014), que estabelece o não surgimento de novas categorias analíticas depois que as explicações, percepções e sentidos nas falas dos entrevistados passa a ter uma constância.

Os encontros para entrevistas foram marcados por telefone e ocorreram nas dependências da instituição de ensino, em sala reservada. Aos que optaram por participar voluntariamente da pesquisa, foi apresentado o Termo de Consentimento Livre e Esclarecido (TCLE) e sanadas eventuais dúvidas. Os depoimentos foram gravados com recurso de um aparelho gravador de voz, de modo a conferir autenticidade às falas apresentadas, para posterior transcrição destas na íntegra. Utilizou-se o pseudônimo DOC (de docente) em caixa alta, seguido da numeração de 01 a 12, definida de acordo com a ordem de execução das entrevistas, certificando sigilo e anonimato a todos os que aceitaram participar do estudo.

Os depoimentos foram interpretados conforme a técnica de "Análise de Conteúdo" de Bardin L (2016), que possibilita sistematização dos dados coletados. Depois de transcritas, as falas foram dispostas segundo a similaridade de ideias para consequente início da discussão.

\section{RESULTADOS E DISCUSSÃO}

Dos 12 enfermeiros, predominou o gênero feminino com 92\%. A faixa etária mais frequente foi acima de 50 anos (42\%). Todos detinham o título de mestre e apenas um não era doutor. Do grupo de doutores, 33\% buscaram aperfeiçoamento no pós-doutorado. Dos entrevistados, $50 \%$ atuavam no ensino da Enfermagem há mais de 10 anos. Esses professores, além de atuarem na graduação, também se dedicavam à especialização $(67 \%)$, ao mestrado $(58 \%)$ e ao doutorado $(50 \%)$. Todos os depoentes dedicavam-se exclusivamente ao ensino na instituição pesquisada e $92 \%$ manifestaram participação em cursos de formação docente.

Foram descritos pelos depoentes os desafios enfrentados para o pleno exercício do "ser professor". Dentre os relatos, muito se falou das dificuldades encontradas relacionados à infraestrutura da instituição, ao alunato, à desvalorização do ensino, às tecnologias, à sobrecarga de trabalho e ao próprio professor.

REAS/EJCH | Vol. Sup. 24 | e300 | DOI: https://doi.org/10.25248/reas.e300.2019 Página 3 de 8 
Os depoimentos dos DOCs $01,03,05,06,07,09$ e 12 demonstram insatisfação quanto à infraestrutura e a falta de materiais na instituição para realização das aulas.

“[...], mas então a gente tem vários desafios aqui, principalmente com relação à estrutura.” - DOC 01

"Especialmente na universidade pública, a gente tem vários desafios, com relação a estrutura... A estrutura física..." - DOC 03

"E a gente tem também em universidade pública que nem sempre tem tudo que a gente precisa, né? Por exemplo, eu acho assim pra você fazer uma prática mais ativa, você precisa de material... Muitas vezes você tem que comprar do seu bolso materiais [...] tem dificuldades de ordens estruturais, físicas da universidade, mas não é só isso, né?" - DOC 05

"Sem ter muita estrutura, apoio financeiro. Até pra você financiar, você consegue financiamento se for pra pesquisa, mas para o ensino não tem, não tem..." - DOC 06

"Hoje, vários aspectos a gente enfrenta, a questão de material, de equipamentos, de logística, isso a gente acaba enfrentando no dia a dia e na prática da docência propriamente dita." - DOC 07

"Inicialmente até de estrutura e de como se organiza essa prática docente [...] e aí a gente lida com vários processos, como salas de aula inadequadas, laboratórios inadequados..." - DOC 09

"Ah, muitos... Primeira coisa que eu acho é a estrutura, a infraestrutura da universidade, porque como eu te falei a gente dá a aula sem um laboratório de informática, o próprio formato das salas de aula... que não dão conta de a gente desenvolver uma metodologia ativa." - DOC 12

A falta de infraestrutura desfavorece a implementação de práticas pedagógicas no ensino ativo, este baseado no envolvimento intenso do aluno no processo de aprendizagem, na comunicação dialógica e no abandono da mera transmissão de conhecimentos. Sátyro N e Soraes S (2007) reiteram que fatores como a existência de uma estrutura adequada com prédios e instalações favoráveis, biblioteca com acesso a livros, espaços, laboratórios, materiais de leitura e pedagógicos, relação conveniente entre o quantitativo de alunos e o docente em sala e maior tempo integral de aula, contribuem na melhoria do ensino.

Neto SJJ et al. (2013) pontuam que quando a escola/instituição possui ambiente de ensino adequado, todos os recursos de aprendizagem conectam-se, permitindo resultados positivos no ensino. Segundo Garcia PS et al. (2014), a estrutura do ambiente de ensino influencia diretamente no trabalho dos professores, bem como, no desenvolvimento dos alunos.

Protagonistas no ensino-aprendizagem, docente e discente têm uma relação didática de reciprocidade. Dentre os desafios encontrados pelos docentes, estão os alunos. Muitos ingressam na universidade jovens, despreparados, inseguros, imaturos e abatidos. Os depoimentos dos DOCs 01, 03, 04, 09 e 11 caracterizaram $o$ aluno o perfil deste aluno.

"Ah, muitas coisas... Alunos desestimulados que ainda tem, ainda tem muitos por aí [...] Às vezes ele chega aqui não muito definido sobre a profissão que ele quer seguir, e aí por talvez ter essa indefinição ele ainda não mergulha no curso como deveria mergulhar." - DOC 01

"Hoje, a gente tem como desafio também o perfil do aluno que a gente recebe, que é um perfil que é bem diferenciado, são jovens, na maioria das vezes indecisos em relação à prática profissional e isso termina, por vezes, sendo um desafio muito grande porque a gente precisa adequar a essa realidade, né?" - DOC 03 
"Hoje a coisa que pra mim é o maior desafio é constatar a discrepância que existe em sala de aula entre o nível de conhecimento e de interesse dos alunos." - DOC 04

"E o aluno também, ele é um desafio hoje. O aluno de dez anos atrás é um aluno totalmente diferente do de agora. Há 10 anos eu era aluna, hoje eu sou professora, vejo como são meus alunos. A gente não tinha uma facilidade de extração como a gente tem hoje. Então os alunos eles estão muito envolvidos com as tecnologias, mas não como uma forma de agregar, mas como uma forma de extrair" - DOC 09

“[...] A própria formação e o jovem de hoje. É um jovem que não tá preparado para ouvir 'não', não sabe ouvir uma crítica como algo construtivo, não tem hábito de leitura, então é um aluno que ele quer o slide pra copiar, decorar e fazer a prova..." - DOC 11

Com o aumento da oferta dos cursos de Enfermagem, vestibulandos ingressam no ensino superior cada dia mais cedo. Consequentemente, a falta de comprometimento com o aprendizado, a base teórica carente, pois são jovens que não possuem o hábito de leitura constante, a ausência de autoconhecimento sobre a sua aprendizagem e a idade inadequada à nova fase acadêmica em que se encontram dificultam o entendimento ao saber lidar com situações novas e adversas trazidas pelas responsabilidades da vida adulta (CORRALMULATO S et al., 2010).

Para Diesel A (2017) existe dualidade nos discursos expostos por professores e alunos. Discentes reprovam aulas rotineiras, monótonas e pouco dinâmicas, enquanto que docentes expõe desapontamento pela participação insuficiente em sala, desinteresse e desvalorização das estratégias criadas para construção de um ensino ativo. Compreende-se, portanto, que o uso de recursos tecnológicos não modifica o cenário de insatisfação coletiva, uma vez que a tecnologia não assegura a plena aprendizagem, tampouco supera 0 ensino passivo, pautado pela memorização de conteúdos ministrados pelo professor.

A desvalorização do ensino e a sobrecarga de trabalho foram outros desafios ilustrados pelos enfermeiros docentes, conforme visto nas falas dos DOCs 05,08 e 09.

"Muitos... Ah, eu acho que a gente trabalha muito como professor... Um deles é esse, eu acho que é muita coisa, principalmente com esse negócio de pós-graduação, graduação a gente trabalha muito [...] Não é fácil ser professor, a gente trabalha aqui, leva muito trabalho pra casa também." - DOC 05

"Eu acho que é essa valorização do ensino mesmo. Assim, hoje a gente tá dentro de uma universidade pública em que é valorizado muito a pesquisa, a pós-graduação, os programas stricto sensu..." - DOC 08

"[...] há uma sobrecarga de atividades, tanto a questão da pós-graduação como a questão da pesquisa em si..." - DOC 09

Os discursos dos DOCs 05, 08 e 09 revelaram jornada exaustiva de trabalho e desvalorização deste campo de atuação do enfermeiro. Frequentemente, o professor leva atividades laborais para sua casa em decorrência do excesso de atividades docentes na instituição. Todos os professores entrevistados trabalhavam em regime de dedicação exclusiva e boa parte, além da graduação, exerciam atividades na pósgraduação, para complemento de carga horária. Observou-se pelas falas dos depoentes uma valorização institucional da pesquisa em detrimento do ensino.

Identifica-se a existência de uma cobrança fundamentada de que os docentes deveriam ser mais produtivos, responder à produção e à quantidade de produtos, como: aulas, orientações, publicações, projetos, congressos, visitas técnicas, etc. Esse exercício representa, na rotina do docente, não apenas uma incorporação desse padrão de produção, mas também a necessidade de criação de condições de sua (re)organização de seu trabalho acadêmico e sua valorização profissional (CUNHA NC e CUNHA TNB, 2015). 
As facilidades tecnológicas também foram lembradas pelos professores como desafios a serem superados. Celulares com acesso à internet podem ser aliados no processo de ensino-aprendizagem, ao mesmo tempo em que podem se tornar grandes vilões. Os discursos dos DOCs 10 e 11 exemplificaram bem a utilização dessas tecnologias.

\begin{abstract}
"A gente tem uma internet que ajuda muito e também atrapalha, porque às vezes o aluno tem acesso a informações que pensa que são corretas e não são [...] Você tem um grande acesso que eu não tive na minha época há 20 anos quando me formei, era só livro na biblioteca." - DOC 10

"E além disso, celular. Celular é uma coisa que destrói a sala de aula. WhatsApp também. 'Ouvi dizer que...', não, não é ouvi dizer, quero saber de onde saiu o fato, 'Já ouvi que fulano usou pra tratamento disso', mas onde você ouviu esse princípio? Foi somente empiricamente? Tudo se joga no Google hoje..." - DOC 11
\end{abstract}

Sabe-se que uso do celular e outros aparatos tecnológicos já fazem parte do cotidiano dos alunos. Professores, diante de tal fato, tentam, ao menos durante suas aulas, fazer com que os discentes abstenhamse de tais tecnologias, pois por mais que seja uma prática silenciosa, o uso do celular reduz a concentração do aluno, e em outras ocasiões é utilizado para atos proibidos pelas instituições de ensino, como a "cola" durante aplicação de provas. Questiona-se até que ponto essas tecnologias podem ser saudáveis em sala de aula.

O uso do celular é uma questão que ainda precisa ser amplamente discutida. A proibição de seu uso em sala de aula pode não impedir a ocorrência de problemas, tendo em vista que os alunos muitas vezes burlam tais limites impostos. Cabe, nesse contexto, bom senso por parte dos alunos e promoção do diálogo por parte do professor, mesmo que seja apenas para justificar os motivos da proibição (BATISTA SCF e BARCELOS GTB, 2013).

Um depoimento interessante partiu do DOC 12, que faz uma crítica ao próprio professor, quando este não exerce seu papel de intervir quando identifica problemas, pelo simples fato de o educador não estar atento e consequentemente não perceber deficiências que poderiam ter sido corrigidas.

"Então que professor é esse, que durante um período todinho não percebe que a pessoa tá faltando, que aquela pessoa não tá entregando as atividades, não tá tendo feedback. Quando chega na prova que ele tira uma nota baixa, você não viu." - DOC 12

Em sua obra "Pedagogia da Autonomia", Freire P (2014) enfatiza que ensinar exige o bom senso do professor. Para ele, o bom senso deve advertir o docente e despertar a autoridade neste em sala, contribuindo assim na tomada decisões, orientação de atividades, estabelecimento de tarefas e cobrança da produção individual e coletiva do grupo. Este bom senso docente não deve ser confundido com autoritarismo, mas sim com autoridade.

Os depoimentos expostos neste estudo colocaram como plano de fundo os desafios que professores enfrentam para construção de um ensino ativo. Falta de infraestrutura e insumos necessários à realização do programado pelos docentes, alunos desmotivados, inseguros e sem conhecimentos prévios, a carga horária de trabalho, a desvalorização do ensino em comparação com outras áreas, como a pesquisa, o uso indiscriminado de tecnologias durante as aulas por parte dos educandos e o próprio docente que, como destacado, não exerce o papel de cobrança do aluno, foram algumas das dificuldades relatadas que precisam ser superados. 
É de fundamental importância que haja valorização docente, com oferecimento de condições dignas de trabalho, salários justos e remodelagem de formação, uma vez que a formação primária do enfermeiro não o prepara ao exercício da docência e a educação continuada acrescenta ao processo educativo, garantindo base teórica necessária ao ensino. Essas estratégias para superação dos desafios podem pautar-se sob a ótica da ação-reflexão-ação, debatendo temas com a finalidade de reverter situações que dificultam a prática docente (RODRIGUES MTP e SOBRINHO JACM, 2008).

\section{CONCLUSÃO}

Obstáculos relacionados à infraestrutura, falta de recursos materiais, carga de trabalho exaustiva e perfil imaturo do alunato são alguns dos desafios evidenciados. Para que haja um ensino de qualidade é importante que todas as dificuldades encontradas neste estudo sejam solucionadas por meio de investimentos em infraestrutura adequada que atenda plenamente aos docentes e ao quantitativo de alunos. Programas de incentivo ao desenvolvimento de aptidões, como os de leitura, desde o ensino básico podem se mostrar relevantes ao passo em que o hábito de leitura é recurso importante na construção de um aprendizado efetivo. A valorização dos professores é essencial para melhoria do ensino ofertado. Motivação, remuneração justa e jornada compatível com os encargos pedagógicos facilitam o envolvimento docente com a instituição de ensino e seus atores. Este estudo traz como contributos a oportunidade de discussão dos entraves no ensino público da Enfermagem atualmente. Conhecer tais dificuldades possibilita transformação da realidade imposta, sendo primordial na elaboração de políticas para superação dos problemas identificados.

\section{AGRADECIMENTOS}

Os sinceros reconhecimentos à Universidade Federal do Piauí, especificamente ao Departamento de Enfermagem, por permitir a execução do estudo na instituição. Um especial agradecimento também deve ser dado aos 12 enfermeiros docentes que exercem o campo de atuação do Ensino com muita responsabilidade, dedicação e compromisso. $O$ aceite voluntário a este estudo mostra o respeito deles pela pesquisa e suas contribuições foram de grande significância.

\section{REFERÊNCIAS}

1. AGNELLI JCM, NAKAYAMA BCMS. Constituição docente do enfermeiro: possibilidades e desafios. Revista @mbienteeducação, 2018; 11(3): 328-344.

2. BARDIN L. Análise de conteúdo. 1a ed. Brasil: Edições 70, 2016.

3. BATISTA SCF, BARCELOS GTB. Análise do uso do celular no contexto educacional. Revista Novas Tecnologias na Educação, 2013; 11(1): 1-10.

4. BRASIL. Lei no 9.394 de 20 de dezembro de 1996. Estabelece as diretrizes e bases da educação nacional. Diário Oficial República Federativa do Brasil, Brasília, no 248, p. 27.833-27.841, dez. 1996.

5. CAMPOS VTB. Docência no ensino superior brasileiro: representações de pós-graduandos de instituições federais de ensino superior. Revista Online de Política e Gestão Educacional, 2012; 2(13): 170-180.

6. CORRAL-MULATO $S$ et al. Docência em Enfermagem: insatisfações e indicadores desfavoráveis. Acta Paulista de Enfermagem, 2010; 23(6): 769-774.

7. CUNHA NC, CUNHA TNB. Intensificação do trabalho docente no ensino superior: significados e condições. Cadernos da Fucamp, 2015; 15(23): 22-40.

8. DIESEL A et al. Os princípios das metodologias ativas de ensino: uma abordagem teórica. Revista Thema, 2017; 14(1): 268-288.

9. FREIRE P. Pedagogia da autonomia: saberes necessários à prática educativa. 53ª ed. São Paulo: Paz e Terra, 2014.

10. GARCIA PS et al. A infraestrutura das escolas de ensino fundamental da Região do Grande ABC paulista. Revista Ibero-Americana de Estudos em Educação, 2014; 9(3): 614-631.

11. INSTITUTO NACIONAL DE ESTUDOS E PESQUISAS EDUCACIONAIS ANÍSIO TEIXEIRA (INEP). Censo da educação superior 2012: resumo técnico. Brasília, 2014. 
12. MINAYO MCS. O desafio do conhecimento: Pesquisa qualitativa em saúde. 14aㅡ ed. São Paulo: Hucitec, 2014.

13. NASCIMENTO VSO. O bacharel e a docência: as influências da pós-graduação na carreira profissional. Holos 2017; 33(2): 280-289.

14. NETO SJJ et al. A infraestrutura das escolas públicas brasileiras de pequeno porte. Revista do Serviço Público, 2013; 64(3): 377-391.

15. PIMENTA SG, ANASTASIOU LGC. Docência no Ensino Superior. 5ª ed. São Paulo: Editora Cortêz, 2014.

16. RODRIGUES MTP, SOBRINHO JACM. Obstáculos didáticos no cotidiano da prática pedagógica do enfermeiro professor. Revista Brasileira de Enfermagem, 2008; 61(4): 435-440.

17. SALES MPS, MACHADO LB. Docência no ensino superior: novo contexto, novas configurações e representações. Atos de Pesquisa em Educação, 2013; 8(2): 500-529.

18. SÁTYRO N, SOARES S. A infraestrutura das escolas brasileiras de ensino fundamental: um estudo com base nos censos escolares de 1997 a 2005. Textos para Discussão nํ 1267. Instituto de Pesquisa Econômica Aplicada (IPEA), Brasília, 2007.

19. VARELA DSS et al. Desafios da prática pedagógica no ensino superior. Revista Expressão Católica, 2016; 5(1): 97103. 